\title{
EDITORIAL: FRAGILITY AND RESISTANCE
}

\author{
Christopher Fox
}

When I was first offered the opportunity of becoming editor of TEMPO one of the things that worried me was topicality: how could a quarterly publication ever engage with the contemporary world? This editorial is the last part of the present issue to be written but even were I tempted to comment on some aspect of this week's news it would be at least three months out of date by the time it appeared in print or on-line. Elsewhere in this issue there are reviews of events which happened before TEMPO 280, the issue before this one, went to press. If it's sometimes hard to keep track of time there is at least the consolation that in TEMPO all time is past.

Over time, however, I have come to realise that this may not be so important. After all, we live in an era where on-line reporting renders all print journalism out of date by the time readers have the newspaper in their hands. But every so often there is a reaction to something we publish here that seems to need a response and after TEMPO 280 was published there was a brief flurry of social media activity, most of it objecting to the tone of some of the reporting of the 2016 Darmstädter Ferienkurse, which was felt to be too harsh, more divisive in its condemnation than was appropriate within the confines of the new music community. In the old days this sort of dissatisfaction might have been translated into a Letter to the Editor; in January 2017 a burst of Twitter and Facebook posts did the business. Perhaps this is to be regretted: a social media flurry leaves less of a trace than a formal complaint and now the only trace will be these few editorial sentences, which will appear almost a year after the event whose reporting caused the flurry.

Some topical events do need comment, however, because their impact is likely to last much longer than three, six, or twelve months and since TEMPO 280 went to press we have started to see evidence of the potential impact of the new administration in the USA. Already the Trump presidency has demonstrated its capacity both for crude chauvinism and for low cunning, using a mixture of misinformation and threats to create a confused cloud of dissent. So public broadcasting and the National Endowment for the Arts, two supporters of new music in the USA, are said to be targets for Trump cuts but, at the time of writing, there are no policy details. Similar cuts are part of the agenda in those European countries where, as in the UK, austerity governments are already in place, or where, as in the Netherlands and France, hard-right parties are campaigning for power.

How should artists respond to this climate of fear and division? This issue of TEMPO offers at least two approaches. In Barbara Jillian Dignam's fascinating survey of currents in recent Irish electroacoustic music she suggests that a 'DIY aesthetic' has emerged in recent years, artists making work outside the conventional modes of production because changes in economic circumstances have restricted their access to the old ways of working. I will leave her to make the argument in more detail, but certainly some of the most powerful music 
created in recent years has happened outside the traditional institutions of artistic support and performance.

On the other hand, is this really DIY? For me DIY is usually a way of doing things less skilfully, probably less durably, out of a desire to save money. When Jennifer Walshe appears with the Arditti Quartet in her EVERYTHING IS IMPORTANT (2016) it is not because they or the promoter are trying to do the piece on the cheap by not hiring a specialist performer, but because she is the specialist performer. This degree of specialisation, creating a set of tools for a very specific task, is the hallmark not of DIY but of craft. Contemporary music is full of similar examples, of software patches designed for a particular piece, of instrumental techniques which may become ubiquitous in a few years times but at present are needed for just one performance situation. In its extraordinary inefficiency this is art as the highest form of economic folly; in the face of a Trump policy matrix which reduces everything to deal-making it also begins to look like a particularly visible form of resistance. Orchestras, choirs, even opera houses, can be made to appear business-like, but devoting time, energy and skill to activities whose economic value is barely measurable? That's how to fight back.

Or, a second approach, a form of resistance based not on vigorous activity but on stillness and quiet: that's what Daniel Wilson and Nomi Epstein propose in their studies of fragility in music. This is music which attempts to change the world not through the noise it makes but because, in making so little noise, it requires a change in the way the world pays attention. It's a subject to which TEMPO will return in our next issue with an article on fragility in the music of Jakob Ullmann by Oliver Thurley. Meanwhile, I would like to thank Martin Iddon and Daniel Wilson for curating this collection of articles on music and fragility and offering them to TEMPO for publication. 